\title{
The thermal performance of window coverings in a whole house test facility with single-glazed sash windows
}

\author{
Richard Fitton • Will Swan • Tara Hughes • \\ Moaad Benjaber
}

Received: 19 August 2015 / Accepted: 8 May 2017

(C) The Author(s) 2017. This article is an open access publication

\begin{abstract}
The residential sector is responsible for $29 \%$ of the total energy consumption of the UK, with $62 \%$ of this energy being used for space heating. Heat loss through the fabric of building elements is a crucial factor in the energy efficiency of homes, and a wide number of studies have looked at physical interventions to improve the energy efficiency of existing buildings, commonly called retrofit. This research considers the impact of window coverings on reducing heat loss from homes, a measure that is not commonly considered an energy efficiency intervention. Although the amount of glazing varies widely between homes, all windows are a significant factor contributing to heat loss. While physical changes such as double and triple glazing can improve the energy performance of buildings, the impact of curtains and blinds is not well characterised. Previous research into window coverings has been undertaken using laboratory tests, such as hotbox and small climatic chamber environments. This study presents the impact of window coverings on heat loss within a unique whole house test facility. This allows for a better replication of a real heating system and the effects that it has on localised heat transfer. This gives a more detailed picture of in situ performance, similar to that which may be found in the field.
\end{abstract}

R. Fitton · W. Swan · T. Hughes · M. Benjaber

School of the Built Environment, Applied Buildings and Energy

Research Group, University of Salford, Salford, UK

R. Fitton $(\bowtie)$

Cockcroft G16, School of the Built Environment, University of

Salford, Salford M5 4WT, UK

e-mail: r.fitton@salford.ac.uk
Keywords Curtains · Blinds · Domestic energy · Windows $\cdot$ Retrofit $\cdot$ Salford Energy House

\section{Introduction}

This study is an investigation into the impact of window coverings, such as curtains and blinds, on the energy efficiency of a house. While previous studies have been undertaken to examine the performance of individual window coverings, this study was carried out in a whole house environmental test facility. This allowed for the consideration of a wider number of factors, such as the impact of localised heating within a controlled environment. This study explored the differences in performance with a heterogeneous distribution of heat throughout the property, as would commonly be found in the field, and to determine the influence of window coverings in comparison to homogenous distribution of heat as is assumed in laboratory tests and many models.

The domestic housing stock is responsible for $29 \%$ of total energy consumption in the UK. A substantial amount of this energy, approximately $62 \%$, is used for space heating (Palmer and Cooper 2013). Reducing heat loss through the fabric of the building through physical interventions is commonly called retrofit (Kelly 2009; Swan et al. 2013). While much retrofit research focuses on major interventions, such as insulation and heating systems, less work has been undertaken on understanding the impact of lower cost but widespread energy efficiency measures, such as controls and window coverings. 
The UK's standard legislative methods of energy modelling the performance of homes, the Standard Assessment Procedure (SAP) and Reduced Data Standard Assessment Procedure (RdSAP) (BRE 2014) make reference to the reduction in heat transfer that curtains and blinds offer, providing an adjustment to $U$ values where window coverings are applied. However, it is not clear whether these values are based on modelled or experimental data. This study aims to quantify, under controlled conditions, the actual energy savings that can be a made using curtains and blinds. The purpose of this research is not to challenge these values but to create a controlled test that will potentially provide accurate values for modellers to use in the future.

Two tests were undertaken to investigate the differences in heat distribution within a property and the potential impact of window coverings with two different heating systems. The first test was carried out using electrical resistance heating, and during the second, gas central heating was used. The first test was used to establish base $U$ value (thermal transmittance) and $R$ value (thermal resistance) measures to allow direct comparison with SAP predictions and previous studies. Electrical heating was used to create a steady-state environment in the room to allow comparisons to be made between different rooms and to allow more accurate $U$ value readings to be taken. The second test, using gas central heating, was undertaken to establish actual heat flow through the windows in a covered and uncovered state. This considered a more realistic environment with more heterogeneous distribution of heat caused by issues, such as emitter placement and different heating set points. This examines heat loss in a more realistic setting to understand the impact of these factors on heat loss.
Both experiments were carried using constant external and internal temperatures at a test house facility within an environmentally controlled chamber to ensure reliable results without variables that might be found in the field such as wind and rain effects or solar gain. These results allowed for more accurate simulation of energy consumption in domestic buildings and greater confidence in the values describing the benefits offered by curtains.

Fabric losses through building elements

When considering buildings from a comfort perspective as the occupant experiences them (Nicol et al. 2012), buildings are designed to protect people within them from extremes of heat, cold or wider boundary conditions such as wind and rain. This means that there is an interrelationship between the boundary conditions, the building fabric, any environmental control system, such as heating and cooling, and the occupant (Hens 2012). Within this study, we consider losses through fabric, specifically glazing, which are generally conductive and radiative losses.

Conductive and radiative losses can be either measured (ISO 1994) or modelled (British Standards Institution 2008). These losses are represented by $U$ values for thermal transmittance and $R$ values for thermal resistance. The $R$ value is the reciprocal of the $U$ value. While the international standard is generally to present $R$ values, where cited research or models indicate $U$ values, we have reported them as such. Figure 1 presents the limiting $U$ values of domestic building elements in the current version of the UK Building Regulations (DCLG 2014). Even in new build
Fig. 1 Limiting $U$ values of domestic building elements in UK Building Regulations (DCLG 2014)

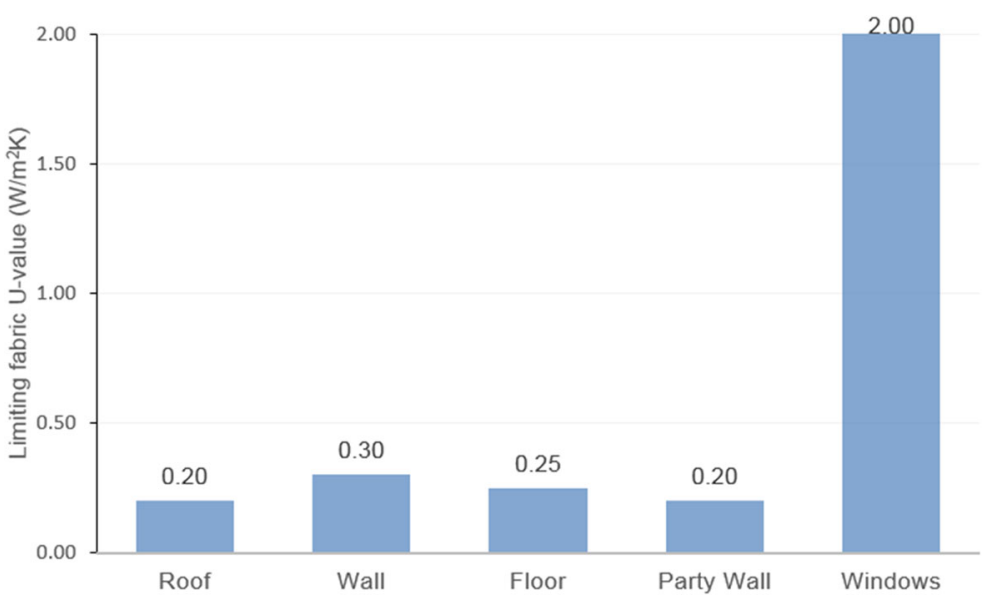


properties, it is apparent that windows are a significant cause of heat loss.

In the UK, most homes have external windows. In comparison with the rest of a building, windows are a major path for heat loss of all types (convective, radiative and conductive). They are also a major pathway for solar radiation gain into the structure. This topic will not be covered in this study.

Heat loss from windows has remained fairly consistent at around $20 \%$ of total heat loss from dwellings over the period 1970-2010 (Palmer and Cooper 2013). During this period, total heat loss from UK dwellings and heat loss from windows have both reduced by almost a third (DECC 2013). These reductions are due to improvements in the building envelope and specifically for windows are due to double glazing and improved frame constructions. Figure 2 shows that despite these improvements, the heat loss from windows is a significant contributor of one fifth of total heat loss from UK dwellings.
Previous studies of window covering thermal performance

Previous studies on window covering cover both curtains and secondary glazing approaches. The studies specifically focus on the reduction of heat transfer through the application of such coverings.

Secondary glazing is specifically designed to provide greater protection from the elements and reduce heat transfer through windows. Secondary glazing ranges from thin films that are stretched or shrunk across windows to framed glass units. Although the $R$ value of secondary glazed windows can be improved by 130 $290 \%$ compared to single glazing (Smith et al. 2012), these units can be expensive, difficult to install and can restrict the use of the windows.

Curtains and blinds are a lower cost intervention, of which there is limited data available with regards to their in situ performance. A number of laboratory-based studies have been carried out to assess the thermal

\section{Total Dwelling Heat Loss and Heat Loss from Windows (Watts/ Kelvin) and Percentage}

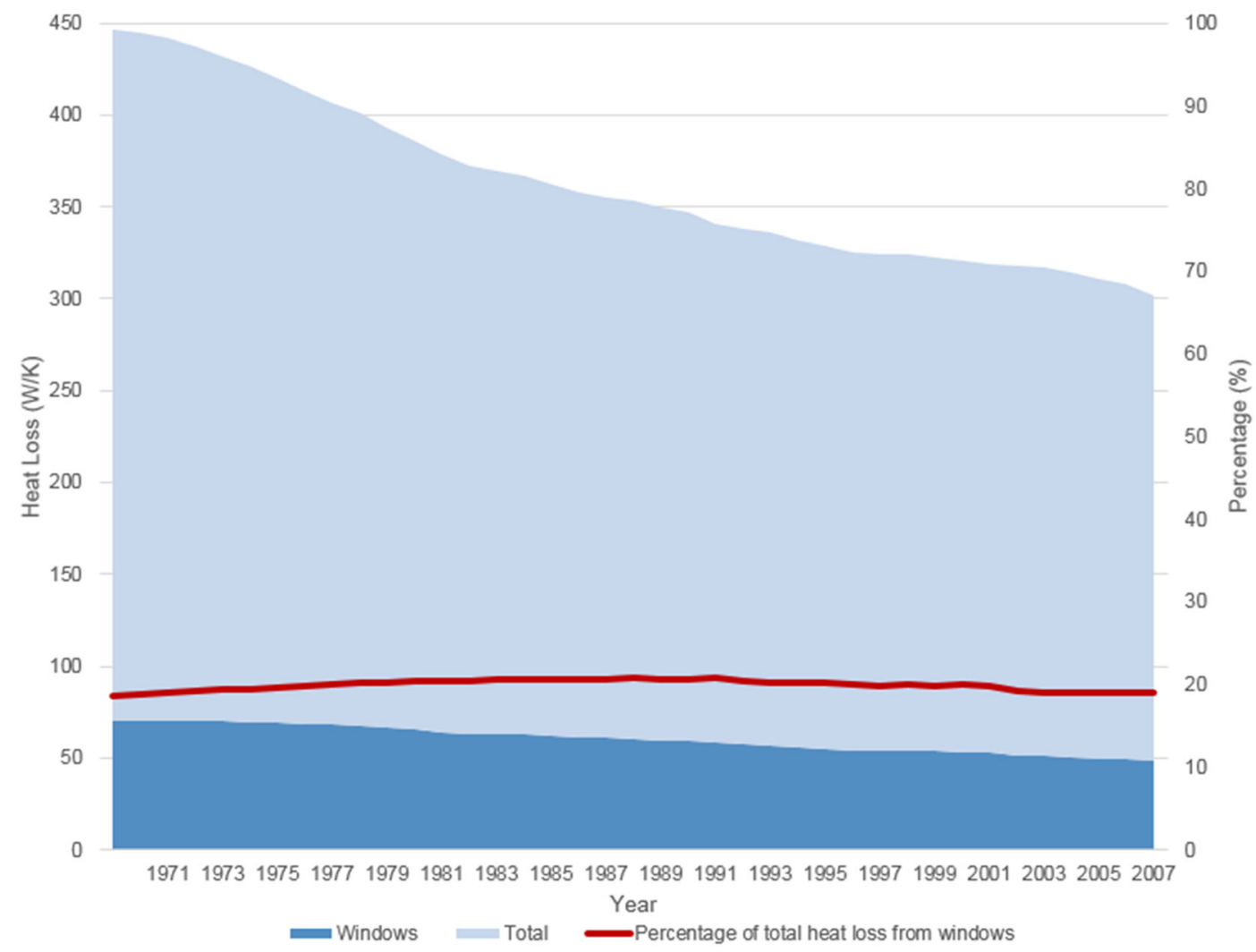

Fig. 2 Total dwelling heat loss and heat loss from windows 1970-2008 (DECC 2013) 
performance of individual window coverings. Baker (2008) identified that energy savings can be achieved with the use of curtains and other window covering systems, ranging from 41 to $62 \%$, while Garber-Slaght and Craven (2012) suggested that savings of $24-38 \%$ were achievable. Table 1 presents a summary of heat transfer reductions suggested by these previous studies as well as the methods used.

As shown in Table 1, there was a range of results for similar coverings. For example, Lunde and Lindley (1988) established a saving of 3.8-9.5\% for curtains, while Baker (2008) suggested a 38\% reduction in heat transfer. These discrepancies could be explained by variations between test set-ups and choice of materials, although this is difficult to establish directly from the literature.

Feather (1980) concluded that substantial savings can be made by using different types of curtain. However, the driving factor was not the actual curtain weight or type, although this was important, but how well the blind was fixed at the perimeter. This fixing creates a layer of stationary air that adds to the insulative effect of the window covering. The way in which a curtain is fitted to the window will affect the amount of heat transferred, with greater levels of airtightness providing better results. The effect of this layer of air is dependent on its width, with a wider air gap providing an increased $R$ value of the window and thus a decrease in the $U$ value (Garber-Slaght and Craven 2012; Nicol 1986; Lunde and Lindley 1988; Ruyssevelt and Littler 1984).

Creating a layer of stationary air is difficult to achieve in practice due to most window coverings, such as curtains and blinds, not being sealed directly to the frame. Fang (2001) used two side-by-side hot boxes to test the $U$ values of single-glazed and double-glazed glass areas without frames, equivalent to the centre of glass of practical windows. The difference in $U$ values between sealed edge curtains and those with a loose edge is shown in Table 2. This illustrates an improved $U$ value of around $19 \%$ with a sealed edged curtain rather than a loose edged curtain on a single-glazed window.

In addition to the differences identified between fixed and loose window coverings, the type of window covering can have a significant effect of heat loss from windows and the location in which the coverings are installed. For example, Wood et al. (2009) found that kitchen and bathroom blinds resulted in savings of 12 and $29 \%$.

Woodson et al. (1986) investigated the thermal resistance of multi-layered window treatments and tested 48 experimental treatments with respect to the four variables of stitching pattern, face fabric, batting material and number of batting layers. The most significant factor was found to be the stitching pattern holding the layers together, with the least number of perforations in the window treatment performing significantly better than those patterns with more stitches.

Table 3 sets out the $R$ values of internal blinds and curtains given in CIBSE Guide A (2015) Table 3.27 based on data from Wood et al. (2009). From these values, the thermal transmittance ( $U$ values) of windows with curtains or blinds was calculated using the formula

$U_{\mathrm{wb}}{ }^{\prime}=\left[\left(1 / U_{\mathrm{w}}\right)+R_{\mathrm{bi}}\right]^{-1}$

where $U_{\mathrm{wb}}$ ' is the thermal transmittance of the window corrected for an internal blind or curtain $\left(\mathrm{W} / \mathrm{m}^{2} \mathrm{~K}\right), U_{\mathrm{w}}$ is the thermal transmittance of the window $\left(\mathrm{W} / \mathrm{m}^{2} \mathrm{~K}\right)$ and $R_{\mathrm{bi}}$ is the thermal resistance of the internal blind or curtain $\left(\mathrm{m}^{2} \mathrm{~K} / \mathrm{W}\right)$ (Formula 3.37 from CIBSE Guide A 2015).

The conversion to $U$ values has been undertaken to allow direct comparison with previous findings. From these, the impact of glazing and fabric window coverings can be observed. This provides a useful baseline for

Table 1 Comparison of results from previous studies

\begin{tabular}{|c|c|c|c|}
\hline Authors & Window covering & $\%$ Reduction in heat transfer & Method \\
\hline \multirow{3}{*}{ Baker (2008) } & Heavy curtains & $39 \%$ & \multirow[t]{3}{*}{ Hotbox environment (controlled) } \\
\hline & Plain roller blind & $37 \%$ & \\
\hline & Insulating blind & $68 \%$ & \\
\hline \multirow[t]{2}{*}{ Garber-Slaght and Craven (2012) } & Insulated blinds & $15 \%$ & \multirow[t]{2}{*}{ In situ testing (uncontrolled winter conditions) } \\
\hline & Curtains & $38 \%$ & \\
\hline \multirow[t]{2}{*}{ Lunde and Lindley (1988) } & Various curtain materials & $3.8-9.5 \%$ & \multirow[t]{2}{*}{ Hotbox environment (controlled) } \\
\hline & Roller blinds & $6.3-38 \%$ & \\
\hline
\end{tabular}


Table 2 Comparison between loose fitting and sealed edge curtains (from Fang 2001)

\begin{tabular}{lllllll}
\hline Window type & \multicolumn{2}{l}{ Sealed edge curtain } & & Loose edge curtain & Percentage difference \\
\cline { 2 - 3 } & $U$ value $\left(\mathrm{W} / \mathrm{m}^{2} \mathrm{~K}\right)$ & $R$ value $\left(\mathrm{m}^{2} \mathrm{~K} / \mathrm{W}\right)$ & & $U$ value $\left(\mathrm{W} / \mathrm{m}^{2} \mathrm{~K}\right)$ & $R$ value $\left(\mathrm{m}^{2} \mathrm{~K} / \mathrm{W}\right)$ \\
\hline Single glazed & 3.66 & 0.27 & 4.44 & 0.23 & $19.26 \%$ \\
Double glazed & 2.16 & 0.46 & 2.58 & 0.39 & $17.72 \%$ \\
\hline
\end{tabular}

the Energy House study and identifies the impact of a wide range of window coverings in terms of their thermal resistance.

Previous research has been carried out under controlled conditions in environmental chambers or in heat flow meter/hot box settings. While this provides a degree of accuracy, the actual energy savings cannot be compared to field-based scenarios as the dynamic of central heating systems and varying room layouts is omitted, with the focus being on the performance of the individual element rather than the element within context. Other trials carried out in the field lack the degree of control and accuracy that the chamber scenarios posses. It is for this reason that a full-scale test facility was chosen to carry out a series of tests on window coverings. This facility not only provides the accuracy of an environmental chamber but also has a heating system, set point and dynamic variability of a real-world scenario.

\section{Methodology}

The research within the Salford Energy House comprised two elements. The first range of tests mimics the steady-state work carried out in environmental chambers and hot boxes, such as Wood et al. (2009). The second aspect of the research is to replicate a real-world whole house test environment, which takes into consideration issues such as emitter locations and airflow within rooms. This presents a more realistic representation of the effect of window coverings in situ, as chamber or hot box tests do not account for the differences between experimental laboratory tests and a whole house context.

\section{Salford Energy House test facility}

The tests were conducted at the University of Salford's Energy House. The Energy House is a full-scale replica of a typical 1910 terraced property from the UK that has been through reasonable modifications, such as heating upgrades. At the time of the validation exercise, the building was uninsulated throughout, with the exception of 100$\mathrm{mm}$ insulation at ceiling joist level. The wooden windows in the property are single-glazed sliding sash-type windows reconstructed to meet the airtightness and thermal transmittance characteristics of the dwelling (Ji et al. 2014).

The Salford Energy House is fully furnished throughout as an occupied two-bedroom dwelling. Although this may influence air movement and heat transfer, it does more closely resemble real homes.

Table $3 R$ and $U$ values for window coverings given in CIBSE Guide A (2015) based on Wood et al. (2009)

\begin{tabular}{|c|c|c|c|}
\hline Description & $\begin{array}{l}\text { Thermal resistance }(R \text { value }) \\
\text { of covering layer }\left(\mathrm{m}^{2} \mathrm{~K} / \mathrm{W}\right)\end{array}$ & $\begin{array}{l}\text { Thermal transmittance } \\
(U \text { value }) \text { of covering } \\
\text { layer }\left(W / \mathrm{m}^{2} \mathrm{~K}\right)\end{array}$ & $\begin{array}{l}\text { Thermal transmittance } \\
\text { ( } U \text { value) of window with } \\
\text { curtains or blinds }\left(\mathrm{W} / \mathrm{m}^{2} \mathrm{~K}\right)\end{array}$ \\
\hline Single glazing only & 0.19 & - & 5.16 \\
\hline Roller blind & 0.14 & 7.14 & 3.03 \\
\hline Heavy curtains & 0.16 & 6.25 & 2.86 \\
\hline Secondary glazing & 0.18 & 5.55 & 2.70 \\
\hline Honeycomb insulated blind & 0.24 & 4.17 & 2.33 \\
\hline Roller blind with low emissivity film on outside face & 0.3 & 3.33 & 2.04 \\
\hline Low emissivity secondary glazing & 0.32 & 3.13 & 1.96 \\
\hline Well-fitting shutters & 0.33 & 3.03 & 1.92 \\
\hline Low emissivity secondary glazing and shutters & 0.39 & 2.56 & 1.72 \\
\hline
\end{tabular}


Experimental design—-test 1

Test 1 consisted of a steady-state analysis of heat transfer across the windows using an elevated and constant temperature provided by electrical resistance heaters in the centre of each occupied room. This provided a steady testing environment to calculate changes in thermal transmittance ( $U$ value) across the centre of the glazing panel using heat flux sensors and temperature sensors. The internal set point for all areas was $25^{\circ} \mathrm{C}$, and the chamber temperature was $5{ }^{\circ} \mathrm{C}$, with a variance of $\pm 0.5^{\circ} \mathrm{C}$. This allows a $\Delta t$ of $20^{\circ} \mathrm{C}$ to be achieved. The temperatures were kept constant throughout the test, which lasted $72 \mathrm{~h}$ in line with the requirements of ISO9869 (ISO 1994). This approach can be seen to replicate hot box or environmental chamber testing, where heat is spread evenly across the element.

Experimental design- - test 2

In test 2, the central heating system in the house was used to heat the building, while using the same heat flux and temperature sensors. This helped build a picture of the actual heat loss through the window pane under standard heating conditions, taking into account the placement of radiators under windows and the increase in heat flow that this can lead to compared to a steadystate electrical heating test, as conducted under test 1.

The gas central heating was used under the following conditions. The Energy House environmental chamber was set at $5^{\circ} \mathrm{C}$, with a variance of $\pm 0.5^{\circ} \mathrm{C}$. This figure is chosen as a UK average winter time temperature, given as $4.9^{\circ} \mathrm{C}$ for the UK in the month of February (BRE 2014). The setpoints within the house, i.e. the internal thermostat settings, were set to $21^{\circ} \mathrm{C}$ in the living room and between 18 and $19^{\circ} \mathrm{C}$ in all other areas as identified in SAP. Each room operated on its own heating control, using either a wall thermostat in the living and a thermostatic radiator valve in all other rooms, a common pattern for many UK homes (DCLG 2015). The internal doors remained closed for the duration of the test to remove the complexity of warm air moving from room to room. It is important to note that some radiators are placed under windows, as is standard for a dwelling of this age and design, and some are placed on external walls. Emitter locations in relation to the window are identified in Table 4.

Instrumentation for $U$ value and heat flow measurement

The purpose of this experiment was to measure heat transfer across the window pane with various window coverings, allowing a $U$ value to be calculated. This was achieved by using heat flux apparatus that complies with the standards laid down in ISO9869 (ISO 1994). This was used to measure both ISO complaint $U$ values and $R$ values for test 1 and heat flow for test 2 .

The system comprised heat flux transducers (HFTs) and temperature sensors. One HFT was fixed to the centre of the pane for each window in the house. Air temperature sensors were fixed at the centre of each room and adjacent to the window in the chamber. The HFTs were Hukseflux HPF-01. The air temperature sensors used were Papouch TH2E semiconductorbased network-attached sensors.

Although ISO9869 does not specify an exact location of temperature measurement, during these experiments, the ambient temperature was measured in the centre of the room. Heaters were placed far enough away from the sensors so as to not directly affect the readings, and spot measurements were taken before testing began to ensure that the air temperature was more or less homogeneous.

Table 4 Experimental matrix setting out window covering type and position in relation to radiator

\begin{tabular}{|c|c|c|c|c|}
\hline Room & Window covering & $\begin{array}{l}\text { Window covering } \\
\text { material }\end{array}$ & $\begin{array}{l}\text { Position of window } \\
\text { in relation to radiator }\end{array}$ & In-use window covering detail \\
\hline Living room & Lined curtain & $\begin{array}{l}\text { Cotton lining, synthetic } \\
\text { face material }\end{array}$ & Above radiator & Curtains tucked behind radiator \\
\hline Kitchen & Roller blind & Polyester & Not adjacent to radiator & Bottom of blind rests on windowsill \\
\hline Bedroom 1 & Lined curtain & $\begin{array}{l}\text { Cotton lining, synthetic } \\
\text { face material }\end{array}$ & Not adjacent to radiator & Curtains drape $25 \mathrm{~cm}$ below windowsill \\
\hline Bedroom 2 & Lined curtain & $\begin{array}{l}\text { Cotton lining, synthetic } \\
\text { face material }\end{array}$ & Not adjacent to radiator & Curtains drape $15 \mathrm{~cm}$ below windowsill \\
\hline Bathroom & Roller blind & Polyester & Above radiator & Bottom of blind rests on windowsill \\
\hline
\end{tabular}


Placing the heaters closer to the window would affect the delta $\mathrm{T}$, but the test was a comparison between open and closed curtains only, and all test conditions remained exactly the same for both cases.

Accuracy and uncertainty

Three variables were measured during this experiment (one of each for each window):

- Hukseflux HFP01 heat flux in Watts (Q) Accurate to within 5\% (Hukseflux 2000).

- Internal Air (C) Accurate to within $0.4{ }^{\circ} \mathrm{C}$ (Papouch 2013).

- External Air (C) Accurate to within $0.4^{\circ} \mathrm{C}$ (Papouch 2013).

Attempts have previously been made to define a standardised error/uncertainty figure with respect to thermal transmission. The international standard for measuring thermal transmission in building elements defines this to be between \pm 14 and $28 \%$ of the thermal transmittance ( $U$ value) (ISO 1994). Baker (2009) favours a statistical error analysis in his paper on a similar series of tests; this gives an uncertainty for the $U$ value of $\approx \pm 5.75 \%$ under these test conditions. Therefore, it will be this figure rather than the ISO figure that will be used due to the suitability to environmental chamber experiments. For field trials, this is less appropriate, and the ISO figure should be used. For heat transfer through the element, the standard figure from the manufacturer is $\pm 5 \%$ (Hukseflux 2000). This figure was used for the heat loss and is applicable to both field and chamber.

As described by Baker (2013), each measured parameter has associated uncertainties, and in order to determine the effect these have on the final $U$ value, the following equation was used:

$$
\mathrm{E}_{\mathrm{rr}} \mathrm{C}=\sqrt{\left(U-U_{\text {errQ }}\right)^{2}+\left(U-U_{\text {erTi }}\right)^{2}\left(U-U_{\text {errTe }}\right)^{2}+(s d)^{2}}
$$

where ErrC is the overall uncertainty of the $U$ value estimate and $U_{\text {errQ }}, U_{\text {errTi }}$ and $U_{\text {errTe }}$ are the $U$ values calculated by applying the errors due to the measured values for heat flux, internal temperature and external temperature.

\section{Calculation method}

The experiments were conducted under steady-state conditions, and although there were slight variances in temperature due to the gas central heating, the electrical system provided a more homogenous temperature within the property. Therefore, a steady-state calculation method was used. This method outputs the average heat flux over the complete testing session; this is deemed to be satisfactory due to the stable testing environments, both internally and chamber wide. The 24-h monitoring period, which was used to calculate average heat flux, was started once the building had reached steady state.

\section{Experimental matrix}

The experiment comprised a whole house solution to window covering. Due to the lack of research with regards to window covering options, an assumed window covering choice was made for each room as outlined in Table 4.

\section{Results}

Test 1 (electrical heating in the centre of room)

The first part of the experiment concentrated on gathering a baseline $U$ value for the windows in a covered and uncovered situation, using electrical heating. The values, as laid out in Table 5, achieved were within measurement limits of expected values, as identified in SAP. These figures are subject to an experimental uncertainty of $\approx \pm 5.75 \%$.

The exception to this was the living room window, where the $U$ value appears to be higher than the remainder of the property. Previous work in the Energy House indicates that this may be attributed to the airflow in this part of the chamber being higher, as the bay protrudes into the airflow of the chamber environment, whereas the other windows are recessed into the wall.

As can be seen in Fig. 3, the heat flux flowing through the window is significantly reduced when the blind is closed in the kitchen and the curtains are drawn in bedroom 1 . 
The second test measured the heat transfer through the window in a typical home, using a standard gas wet central heating system. This allowed a greater concentration of heat to flow through the window depending on the location of the heat source in the room. It more closely reflects the actual heat loss that might be found in a normal domestic dwelling, where radiators are often placed below windows.

As can be seen from Fig. 4, when using a gas central heating system, there is greater fluctuation in measured temperatures. It is important to note that the two drops in heat flux show the effect of closing the curtains and blinds at the beginning of the test and data from this period was not used for analysis.

Table 6 shows the measured heat flux during the second test. While the figures in Tables 5 and 6 may seem relatively straightforward, the baseline heat loss and the reductions in terms of energy transfer are significantly different across the array of windows. This is due to a number of variables affecting each window in each room.

The variables include the air temperature of the room; while the chamber maintains a standard $5^{\circ} \mathrm{C}$, the room temperatures have been set at $21^{\circ} \mathrm{C}$ in the living room and $18-19^{\circ} \mathrm{C}$ in all other areas. This will lead to a greater amount of heat flux through the living room. The distance from the heat source to the window also appears to have an impact, with some rooms having the radiator located directly underneath the window (living room and bathroom) and which have the highest heat loss rate when uncovered, whereas other rooms (bedroom 1 and bedroom 2) have the lowest heat flux across the window, as the radiator is placed across the room from the window. The contradiction to this point is the kitchen, which has a relatively high heat loss, but the radiator is located some way across the room. However, the combination boiler is placed directly next to this window and will generate a higher rate of heat flux through the adjacent window.

\section{Discussion}

There is little published literature with regards to the use of curtains in UK homes. This suggests a gap in knowledge of how curtains are used and the implications and opportunities for energy savings and should be investigated further.

The focus of the research was firstly to establish $U$ values for windows and their coverings and compare 


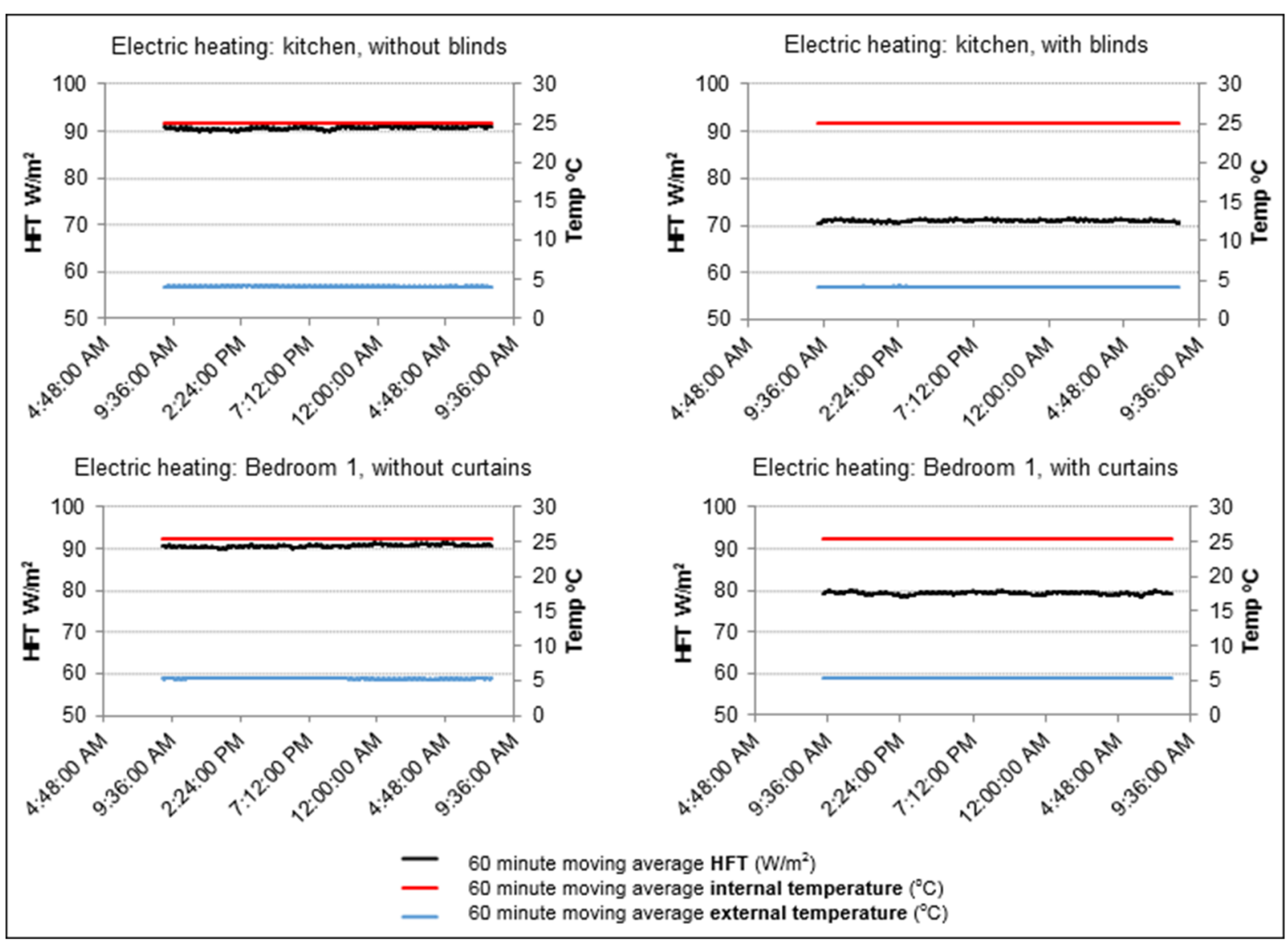

Fig. 3 Graphs of heat flux and measured temperatures in the kitchen and bedroom 1, with and without window coverings when electric heating is used

these with existing models. The second issue was to identify the differences in these values between homogenous heat distribution, as assumed by many steady-state models such as SAP, and heterogeneous heat distribution as is more commonly found in buildings in situ.

Comparison with standardised UK models and guidance

The effective $U$ value for windows, taking into account the assumed use of curtains, is calculated using the following formula from SAP2012:

$$
U_{\mathrm{w}, \text { effective }}=\frac{1}{\frac{1}{U_{\mathrm{w}}}+0.04}
$$

where $U_{\mathrm{w}}$ is the window $U$ value calculated of measured without curtains. The $U$ values under electrical heating, i.e. homogenous heat distribution throughout the property, compared closely with both previous studies and the assumptions within SAP. As seen in Table 7, the $R$ values are also comparable with the assumed $R$ values of SAP, taking into consideration measurement error.

The differences between measured and modelled values are not significant and vary between positive and negative differences; the mean of these figures gives an overall difference of just $0.07 \mathrm{~W} / \mathrm{m}^{2} \mathrm{~K}$. It is not possible to say definitively whether the SAP model overestimates or underestimates the savings offered by window coverings, due to the low number of measures and cases within the study. However, when the results are separated into curtains and blinds, it appears that there may be a significant underestimation in SAP on the potential energy savings from the use of blinds. When blinds are considered in isolation, SAP calculates a higher $U$ value by an average of $0.05 \mathrm{~W} / \mathrm{m}^{2} \mathrm{~K}$, and curtains generally a lower $U$ value on average of 


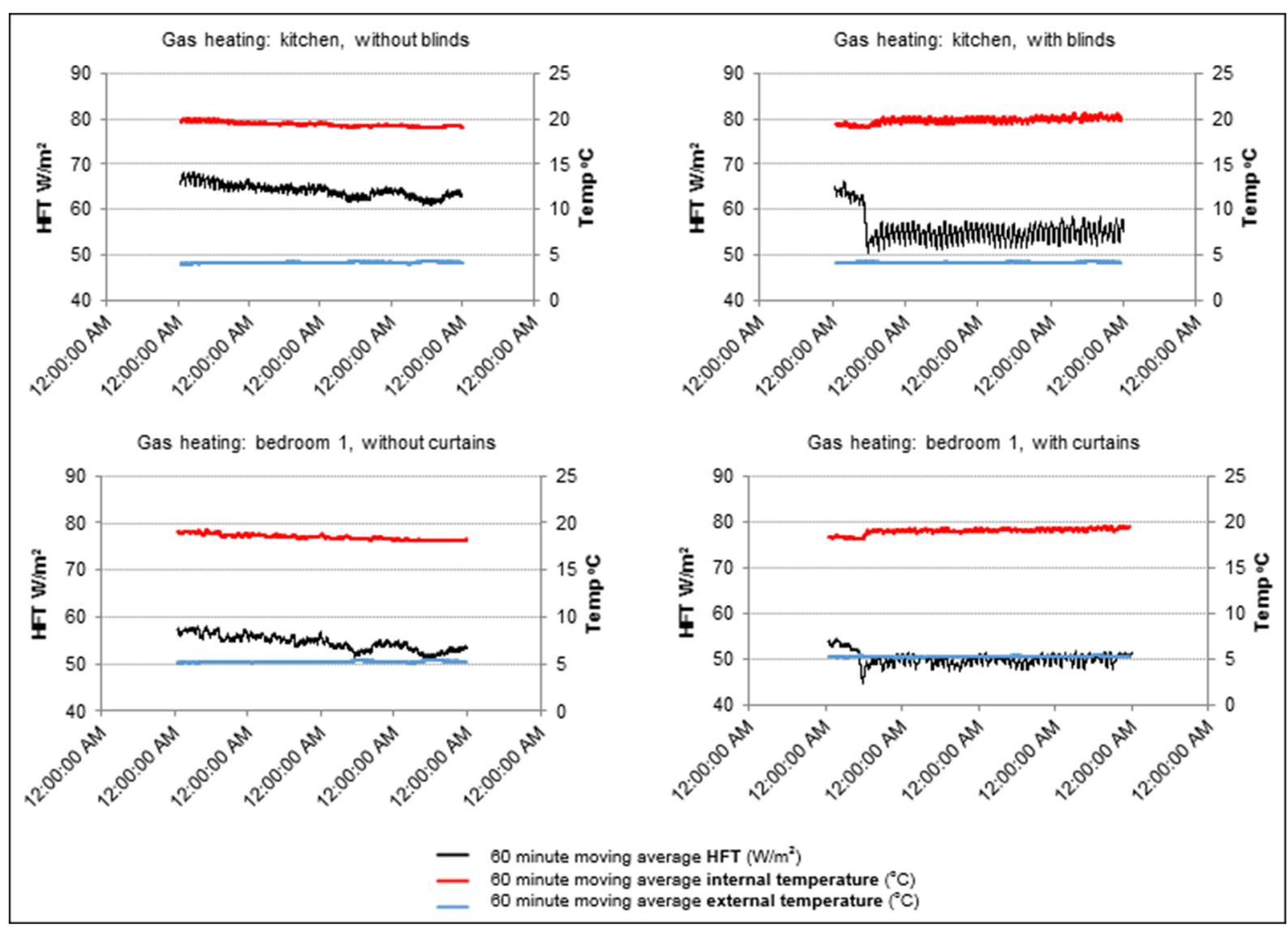

Fig. 4 Graphs of heat flux and measured temperatures in the kitchen and bedroom 1 with and without window coverings when using gas central heating

$0.07 \mathrm{~W} / \mathrm{m}^{2} \mathrm{~K}$. These figures are all within the boundaries of the measurement error and, while potentially indicative of an issue, are not conclusive.

When the resulting $U$ values from the electric heating test are compared with those presented in the table from CIBSE Guide A (2015) and Wood et al. (2009), it can be seen that there were differences. Some of these differences may be accredited to differences in the exact types of window coverings specified by Guide A, for instance, although the curtains in the Salford Energy House are lined, they may not be considered to be heavy curtains.
As can be seen from Table 8, the differences between actual and expected $U$ values were greatest in the rooms that had curtains rather than blinds.

Air spaces are a significant contributing factor to the overall $U$ value of the window when considering savings made by curtains (Fang 2001; Wood et al. 2009). Their research confirms the standard method of calculating a $U$ value where curtains are concerned, which stipulates that a standard air layer should be used to make the calculation. This research presented here found that this was not required in curtains that did not make any seal to the window

Table 6 Gas central heating measured heat flux

Living room Kitchen blind Bedroom 1 Bedroom 2 Bathroom blind

\begin{tabular}{|c|c|c|c|c|c|}
\hline Without coverings average measured heat flux over $24 \mathrm{~h}\left(\mathrm{~W} / \mathrm{m}^{2}\right)$ & 96.42 & 62.91 & 52.81 & 62.01 & 63.11 \\
\hline With coverings average measured heat flux over $24 \mathrm{~h}\left(\mathrm{~W} / \mathrm{m}^{2}\right)$ & 69.66 & 55.15 & 50.20 & 55.65 & 44.72 \\
\hline Savings $\left(\mathrm{W} / \mathrm{m}^{2}\right)$ & 26.76 & 7.76 & 2.61 & 6.36 & 18.39 \\
\hline Savings $(\%)$ & 27.75 & 12.34 & 4.94 & 10.26 & 29.14 \\
\hline
\end{tabular}


Table 7 Comparison between SAP prediction and measured $R$ values in test 1

\begin{tabular}{|c|c|c|c|c|c|}
\hline & Living room & Kitchen & Bedroom 1 & Bedroom 2 & $\begin{array}{l}\text { Bathroom } \\
\text { blind }\end{array}$ \\
\hline Measured $R$ value without curtains average over $24 \mathrm{~h}\left(\mathrm{~m}^{2} \mathrm{~K} / \mathrm{W}\right)$ & $0.20 \pm 0.01$ & $0.23 \pm 0.01$ & $0.22 \pm 0.01$ & $0.22 \pm 0.01$ & $0.23 \pm 0.01$ \\
\hline$R$ value with curtains average over $24 \mathrm{~h}\left(\mathrm{~m}^{2} \mathrm{~K} / \mathrm{W}\right)$ & $0.24 \pm 0.01$ & $0.29 \pm 0.02$ & $0.25 \pm 0.02$ & $0.25 \pm 0.02$ & $0.29 \pm 0.02$ \\
\hline Measured delta $R$ value $\left(\mathrm{m}^{2} \mathrm{~K} / \mathrm{W}\right)$ & $0.05 \pm 0.003$ & $0.06 \pm 0.004$ & $0.03 \pm 0.002$ & $0.03 \pm 0.002$ & $0.06 \pm 0.004$ \\
\hline $\begin{array}{l}\text { Predicted } R \text { values with coverings according to SAP } 2012 \\
\quad \text { (measured } R \text { value without curtains }+0.04)\left(\mathrm{m}^{2} \mathrm{~K} / \mathrm{W}\right)\end{array}$ & 0.24 & 0.27 & 0.26 & 0.26 & 0.27 \\
\hline Difference between SAP prediction and measured $R$ value & 0 & 0.02 & -0.01 & -0.01 & 0.02 \\
\hline
\end{tabular}

reveal. For steady-state heating when using curtains, the effect on the $U$ value of the window is the only addition of an extra layer of resistance provided by the curtain.

The impact of heterogeneous heat distribution on heat transfer

Data suggests that steady-state homogenous air temperature models may not accurately reflect the potential savings that can be achieved with window coverings. It is also clear that in real-world situations where radiators are placed at different locations in each room, the opportunity to make energy savings regardless of covering type is at the locations with the greatest proximity to emitters, either directly underneath or adjacent to the windows. This has implications for steady-state models such as SAP where savings are generated using an average mean room temperature.

Further to energy efficiency, thermal comfort is clearly a significant issue in domestic dwellings (Lunde and Lindley 1988). Curtains can affect the rate of convection around a room and prevent some air infiltration and exfiltration, in particular when used with leaky windows such as the sliding sash windows at the Energy House. More research is needed on how the curtains in a room can affect the thermal comfort levels in a room and how this may be improved.
Another important factor to consider is that single glazing also poses a significant risk to surface condensation in buildings with high humidity levels due to the high conductivity levels and the consequential low surface temperatures. The addition of an extra layer of resistance to the internal face of the window element will have the effect of lowering the surface temperature considerably during the heating season. Models such as WUFI can be used to predict and help mitigate these situations (May and Sanders 2014).

\section{Conclusions}

This study set out to establish the impact of window coverings on a single-glazed sash window within a whole house context under controlled conditions. The data from test 1 , which was under homogenous electrically heated conditions, suggest a broad agreement with other studies carried out under controlled conditions. Test 2, however, indicates that much higher rates of heat loss occur when the heating emitter is adjacent to the window, as is common in UK domestic heating systems. This means that steady-state models such as SAP may not accurately represent the actual heat loss through the window element, whereas more $3 \mathrm{D}$ dynamic simulation modelling may

Table 8 Comparison between expected and actual $U$ values in test 1

\begin{tabular}{|c|c|c|c|c|c|}
\hline & $\begin{array}{l}\text { Living } \\
\text { room }\end{array}$ & $\begin{array}{l}\text { Kitchen } \\
\text { blind }\end{array}$ & $\begin{array}{l}\text { Bedroom } \\
1\end{array}$ & $\begin{array}{l}\text { Bedroom } \\
2\end{array}$ & $\begin{array}{l}\text { Bathroom } \\
\text { blind }\end{array}$ \\
\hline Without coverings $U$ value average over $24 \mathrm{~h}\left(\mathrm{~W} / \mathrm{m}^{2} \mathrm{~K}\right)$ & 5.10 & 4.32 & 4.50 & 4.45 & 4.43 \\
\hline $\begin{array}{l}\text { Comparison with expected } U \text { value (from Table } 3.27 \text { CIBSE Guide } \\
\text { A; } 5.16 \mathrm{~W} / \mathrm{m}^{2} \mathrm{~K} \text { for single glazing only) difference }\end{array}$ & -0.06 & -0.84 & -0.66 & -0.71 & -0.73 \\
\hline With coverings average $U$ value over $24 \mathrm{~h}\left(\mathrm{~W} / \mathrm{m}^{2} \mathrm{~K}\right)$ & 4.13 & 3.40 & 3.93 & 3.96 & 3.49 \\
\hline $\begin{array}{l}\text { Comparison with expected } U \text { values (from Table } 3.27 \text { CIBSE Guide A; } 2.86 \mathrm{~W} \text { / } \\
\mathrm{m}^{2} \mathrm{~K} \text { for heavy curtains and } 3.03 \mathrm{~W} / \mathrm{m}^{2} \mathrm{~K} \text { for roller blinds) difference }\end{array}$ & +1.27 & +0.37 & +1.07 & +1.10 & +0.46 \\
\hline
\end{tabular}


address this issue by providing a greater level of accuracy. The convective nature of central heating systems means that placing heating emitters under windows improves the convective flow of heat through a room; this will lead to greater heat loss through covered window elements. However, this does have implications for their performance and how they are represented in models. Potentially, this could be used to identify the greater heat losses of these windows when replacement windows are being installed.

This work is the first stage of a series of studies that will be carried out on window coverings by the Salford Energy House team. This study provides baseline data and methodological approaches for further work with regards to airtightness improvements offered by window coverings through the reduction of drafts, thermal comfort issue-based operative temperature readings, dynamic modelling of energy and commensurate cost savings of window coverings and heat up and cool down times of rooms with and without window coverings. Additionally, these are baseline steady-state tests. It is felt that undertaking more dynamic testing and modelling could provide a more detailed insight into longer term data for energy savings for this type on intervention.

\section{Compliance with ethical standards}

Conflict of interest The authors declare that they have no conflict of interest.

\section{Appendix Photographs of room layouts}

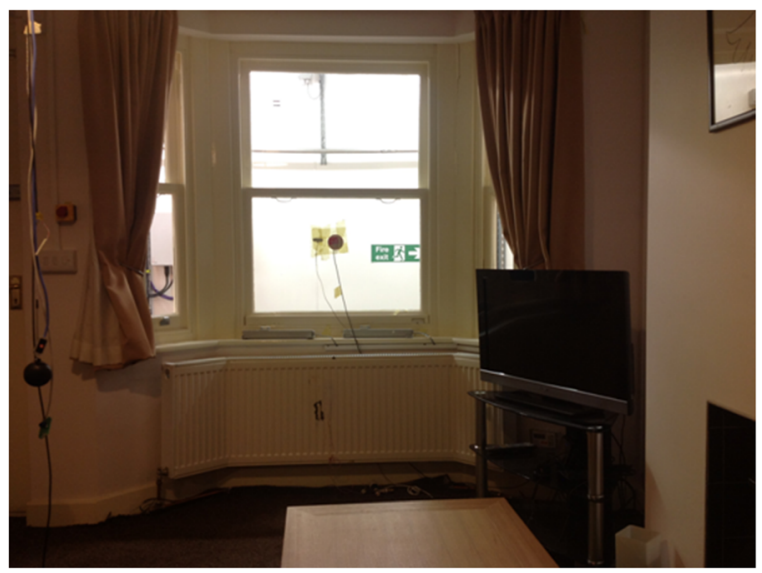

Fig. 5 Living room with lined curtains and radiator directly beneath window

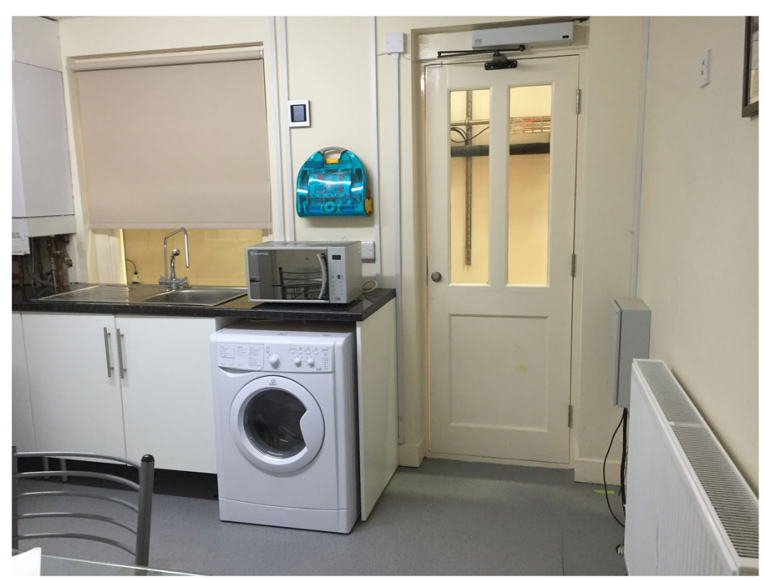

Fig. 6 Kitchen with roller blind and radiator not in close proximity to window

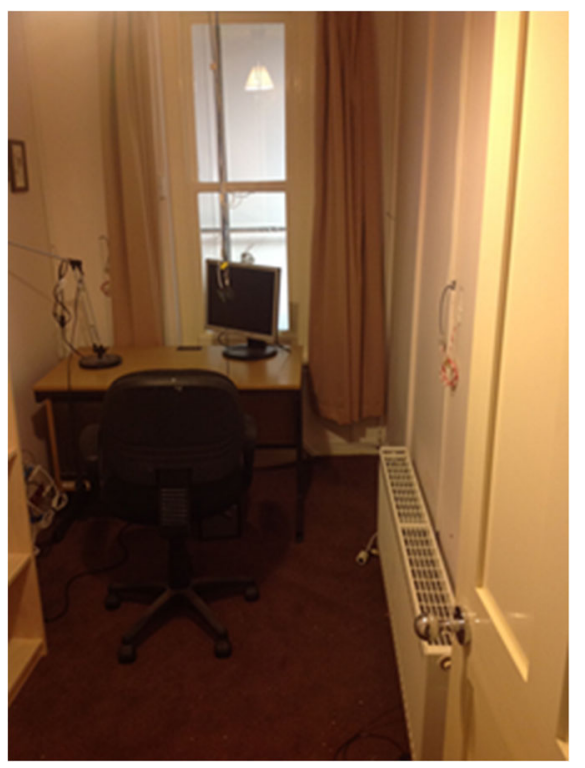

Fig. 7 Bedroom 2 with lined curtains and radiator not in close proximity to window

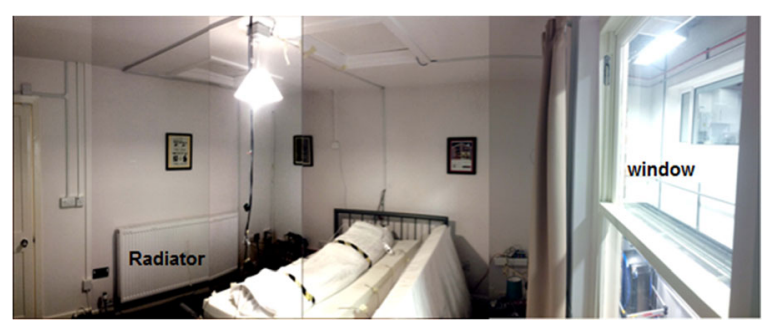

Fig. 8 Bedroom 1 with lined curtains and radiator on opposite wall 


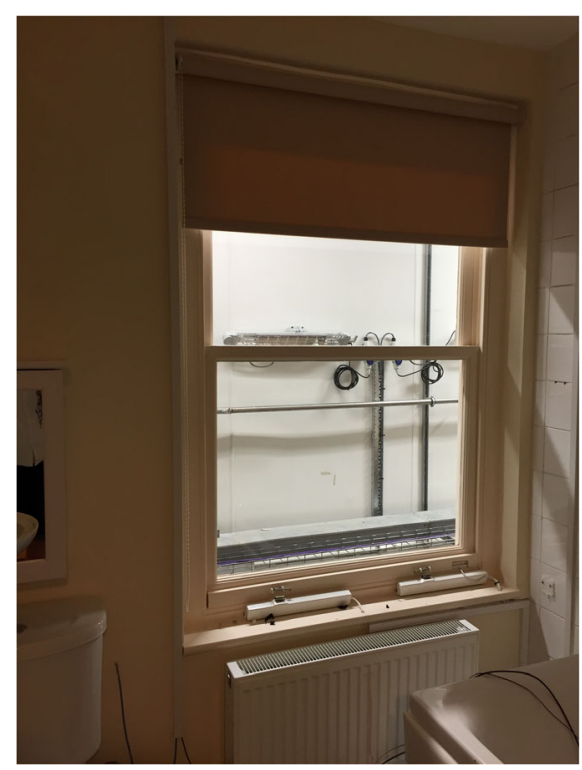

Fig. 9 Bathroom with roller blind and radiator directly beneath window

Open Access This article is distributed under the terms of the Creative Commons Attribution 4.0 International License (http:// creativecommons.org/licenses/by/4.0/), which permits unrestricted use, distribution, and reproduction in any medium, provided you give appropriate credit to the original author(s) and the source, provide a link to the Creative Commons license, and indicate if changes were made.

\section{References}

Baker, P. (2008). Thermal performance of traditional windows. Technical paper 1. Edinburgh: Historic Scotland.

Baker, P. (2009). Research into the thermal performance of traditional windows: timber sash windows. Portsmouth: Historic England.

Baker, P. (2013). Research into the thermal performance of traditional walls: solid brick walls. Portsmouth: Historic England.

BRE. (2014). The government's standard assessment procedure for energy rating of dwellings (SAP 2012). Watford: BRE.

British Standards Institution. (2008). BS EN ISO 6946:2007. Building components and building elements. Thermal resistance and thermal transmittance. Calculation method. London: BSI.

CIBSE. (2015). CIBSE Guide A: Environmental Design 2015. London: CIBSE ISBN:9781906846541.

Department for Communities and Local Government. (2014). Building regulations approved document L1A: conservation of fuel and power in new dwellings (2013th ed.). London: DCLG ISBN: 978-1-85946-510-3.

Department for Communities and Local Government. (2015). English housing survey: households 2013-14. London: DCLG ISBN: 978-1-4098-4642-0.

Department of Energy and Climate Change. (2013). United Kingdom's housing energy fact file: tables and graphs. London: DECC URN:13D/277.
Fang, X. (2001). A study of the U-factor of a window with a cloth curtain. Applied Thermal Engineering, 21(5), 549-558. doi:10.1016/S1359-4311(00)00071-5.

Feather, B. L. (1980). Window treatments and energy conservation. Journal of Interior Design, 6(2), 43-46. doi:10.1111/j.1939-1668.1980.tb00304.x.

Garber-Slaght, R., \& Craven, C. (2012). Evaluating window insulation for cold climates. Journal of Green Building, 7(3), 3248. doi:10.3992/jgb.7.3.32.

Hens, H. (2012). Building physics—heat, air and moisture: fundamentals and engineering methods with examples and exercises (2nd ed.). New York: Wiley ISBN: 978-3-433-03027-1.

Hukseflux (2000). Application and specification of heat flux sensors. Hukseflux. Retrieved from http://www.hukseflux. com/downloads/thermalScience/applicAndSpec.pdf.

ISO. (1994). ISO 9869:1994(E) thermal insulation-building elements - in-situ measurement of thermal resistance and thermal transmittance. Geneva: ISO.

Ji, Y., Fitton, R., Swan, W., \& Webster, P. (2014). Assessing overheating of the UK existing dwellings - a case study of replica Victorian end terrace house. Building and Environment, 77, 1-11. doi:10.1016/j.buildenv.2014.03.012.

Kelly, M. J. (2009). Forum retrofitting the existing UK building stock. Building Research and Information, 37(908304030), 196-200. doi:10.1080/09613210802645924.

Lunde, H. A., \& Lindley, J. A. (1988). Effects of window treatments in cold climates. Home Economics Research Journal, 16(3), 222-234. doi:10.1177/1077727X8801600307.

May, N., \& Sanders, C. (2014). Moisture risk assessment and guidance. London: STBA.

Nicol, K. (1986). The thermal effectiveness of various types of window coverings. Energy and Buildings, 9(3), 231-237. doi:10.1016/0378-7788(86)90023-X.

Nicol, F., Humphreys, M., \& Roaf, S. (2012). Adaptive thermal comfort: principles and practice. Oxon: Routledge ISBN: 9780415691598.

Palmer, J., \& Cooper, I. (2013). United Kingdom housing energy fact file 2012. London: DECC.

Papouch (2013). Retrieved Mar 20, 2015, from http://www. papouch.com/en/shop/product/th2e-ethernet-thermometerhygrometer/.

Ruyssevelt, P., \& Littler, J. (1984). In H. Ehringer \& U. Zito (Eds.), Energy saving in buildings. Dordrecht: Springer. doi:10.1007 /978-94-009-6409-9.

Smith, N., Isaacs, N., Burgess, J., \& Cox-Smith, I. (2012). Thermal peformance of secondary glazing as a retrofit alternative for single-glazed windows. Energy and Buildings, 54, 47-51. doi:10.1016/j.enbuild.2012.07.038.

Swan, W., Ruddock, L., Smith, L., \& Fitton, R. (2013). Adoption of sustainable retrofit in UK social housing. Structural Survey, 31(3), 181-193. doi:10.1108/SS-12-2012-0039.

Wood, C., Bordass, B., \& Baker, P. (2009). Research into the thermal performance of traditional windows: timber sash windows: executive summary. Portsmouth: English Heritage.

Woodson, E. M., Horridge, P., \& Khan, S. (1986). Interior insulators: problem solvers at the window. ASHRAE Transactions, 92(1A), 439-452. 